\title{
Depoimento Sem Dano e as Inovações Trazidas Pela Lei $\mathrm{N}^{\circ} 13.431 / 2017^{1}$
}

Anna Gesteira Bäuerlein Lerche Valsani ${ }^{2}$ Izabella Drumond Matosinhos ${ }^{3}$

\section{RESUMO}

A prática de crimes violentos, principalmente sexuais, atinge grande camada da população brasileira e, em especial, crianças e adolescentes, em regra, pessoas mais vulneráveis a este tipo de violência. A maneira como tem sido tomado o depoimento dessas crianças e adolescentes, em ambientes desconhecidos (delegacia ou sala de audiência judicial), sem que haja preparo técnico dos operadores do direito, traz maiores danos àqueles, causando a chamada revitimização secundária ou violência institucional, em que a vítima ou testemunha revive toda a situação de violação já experimentada. Há muito tempo, tem-se pensado em formas de propiciar esses depoimentos, que, muitas vezes, são a única fonte de prova, sem provocar tais efeitos danosos. A Lei no 13.431/2017 sistematizou, pela primeira vez, os institutos da escuta especializada e do depoimento especial, sendo, portanto, importante avanço para o ordenamento jurídico brasileiro.

1 Data de recebimento: 28/11/2017. Data de aceite: 19/01/2018.

2 Membro do Ministério Público do Estado do Ceará. Promotora de Justiça titular da Promotoria de Justiça de Paracuru. Bacharel em Direito pela Universidade de Sorocaba-SP (UNISO). Pós-graduada em Direito Público pela Universidade Potiguar (UNP). E-mail: anna.valsani@mpce.mp.br

3 Membro do Ministério Público do Estado do Ceará. Promotora de Justiça titular da $3^{a}$ Promotoria da Comarca de Morada Nova, pós-graduada em Direito Público pela Universidade Cândido Mendes, Bacharel em Direito pela Pontifícia Universidade Católica de Minas Gerais (PUC-MG), Bacharel em Ciências Sociais pela Universidade Federal de Minas Gerais. E-mail: izabella.drumond@mpce.mp.br 
Palavras-chave: Criança e Adolescente. Proteção Integral. Vitimização Secundária. Escuta Especializada. Depoimento Especial.

\section{INTRODUÇÃO}

A violência, em todas as suas formas, contra a criança e o adolescente é um fenômeno de extrema gravidade, muitas vezes socialmente aceito, que pode gerar diversas consequências que ultrapassam os danos puramente físicos.

De acordo com os últimos dados do balanço das denúncias de violação de direitos humanos, feitas através do Disque 100, divulgados pela Secretaria dos Direitos Humanos ${ }^{4}$, 56,6\% das denúncias recebidas em 2016 são relativas à violência contra a criança e o adolescente, seja ela psicológica, física e sexual.

Os números ainda revelam que $57 \%$ das denúncias feitas pelo Disque 100 são relacionadas a algum tipo de violação de direito de crianças e adolescentes.

Embora causem certo impacto, esses dados ainda podem representar apenas uma parte da realidade, já que parcela considerável das violações não é descoberta por meio de denúncias realizadas pelo disque 100, mas por órgãos de proteção da criança e do adolescente localizados nos municípios, como Conselho Tutelar, CREAS, Delegacia de Polícia, Ministério Público, entre outros.

Têm sido cada vez mais frequentes estudos que demonstram que pessoas que experimentam situação de violência, seja como vítima ou testemunha, podem sofrer algum tipo de trauma que traz consequências para o resto de suas vidas.

Por outro lado, em regra, em crimes que envolvem violência contra a pessoa, o depoimento das vítimas e testemunhas têm especial valor probatório, sendo praticamente impossível descartá-lo como meio

4 Disponível em http://www.mdh.gov.br/disque100/balancos-e-denuncias/balanco-disque-100-2016-apresentacao-completa/ 
de prova, a despeito dos danos eventualmente gerados.

Dessa forma, necessário se faz a criação de mecanismos que preservem a produção da prova testemunhal, e busquem minorar os agravos sofridos por quem foi vítima ou testemunha de crime violento. E, em se tratando de criança e adolescente, que se encontram em condição peculiar de desenvolvimento, o cuidado deve ser redobrado.

Como é cediço, o sistema da proteção integral da criança e do adolescente encontra-se bem consolidado, ao menos em tese, no ordenamento jurídico brasileiro. A Constituição Federal e o Estatuto da Criança e do Adolescente são os responsáveis pela previsão da proteção integral e, em consequência, de amplo leque de direitos materiais das crianças e dos adolescentes no direito brasileiro.

No entanto, havia uma lacuna processual de mecanismos de proteção de vítimas e testemunhas infantojuvenis de crimes praticados mediante violência, razão pela qual foi promulgada a Lei 13.431/17, visando cumprir obrigação assumida pelo Brasil na Convenção dos Direitos da Criança e nos Protocolos Adicionais, em especial, o que tratou da venda, exploração e pornografia de criança.

Dentre outras inovações, foram trazidos pela lei em comento mecanismos processuais para a garantia dos interesses dos menores que precisam ser ouvidos durante a persecução criminal de delito violento.

Assim, diante da recente promulgação da Lei 13.431/17 e da sua iminente vigência ${ }^{5}$, foi feito o presente trabalho, que tem como objetivo geral analisar os novos institutos trazidos pelo diploma legal e debater o tema, contribuindo para discussão teórica e prática da matéria.

Acredita-se que esses institutos podem ser extraídos da doutrina da proteção integral da criança e do adolescente, e que vêm preencher o espaço que havia na legislação menoril, ao prever expressamente

5 A Lei $n^{\circ} 13.431 / 2017$ foi publicada no dia 05 de abril de 2017, no entanto, só entrará em vigor a partir do dia 06 de abril de 2018. 
mecanismos processuais específicos de proteção de vítimas e testemunhas de crimes violentos.

Para a realização do presente trabalho e discussão do tema proposto, foi utilizada como metodologia a pesquisa bibliográfica e jurisprudencial, por meio da investigação realizada em livros, artigos e jurisprudência acerca do tema.

Dessa forma, no primeiro capítulo, discorremos sobre a proteção integral da criança e do adolescente, doutrina que fundamenta todo o sistema de defesa infanto-juvenil e, assim, embasou a elaboração da lei em questão. No segundo capítulo, foram trazidos alguns princípios específicos da disciplina menoril relacionados, não só à lei em espeque, mas à própria doutrina da proteção integral.

Já no terceiro capítulo, a Lei 13.431/17 foi o objeto propriamente dito do estudo, tendo sido feita uma breve análise dos antecedentes legais, dos destinatários da lei, as formas de violência e dos direitos e garantias específicos por ela trazidos, dentre eles a escuta especializada e depoimento especial.

Ao final, concluímos sobre a importância dos novos institutos trazidos pela lei, não só como forma de evitar a revitimização de crianças e adolescentes vítimas ou testemunhas de violência, mas como meio de produção de prova, de acordo com o devido processo legal.

\section{DOUTRINA DA PROTEÇÃO INTEGRAL}

A doutrina da proteção integral, inspirada na Convenção dos Direitos da Criança e adolescente, foi introduzida no ordenamento jurídico brasileiro a partir da Constituição Federal de 1988.

Pela primeira vez o ordenamento jurídico constitucional impôs ao legislador infraconstitucional o dever de tratar a criança e o adolescente como sujeitos de direito, e não mais como meros objetos de intervenção dos adultos.

Segundo Andrea Rodrigues Amin (2014), a doutrina da proteção 
integral rompe o padrão até então estabelecido e absorve os valores previstos na Convenção dos Direitos da Criança. É a primeira vez que crianças e adolescentes titularizam direitos fundamentais, como qualquer ser humano. Passamos, assim, a ter um Direito da Criança e do Adolescente, que é amplo, abrangente, universal e, acima de tudo, exigível, substituindo o chamado Direito do Menor, até então vigente.

Assim, em apertada síntese, pode-se afirmar que a proteção integral do menor em desenvolvimento nada mais busca do que garantir a efetividade dos direitos inerentes à dignidade da pessoa humana, como saúde, educação, convivência social, lazer, liberdade, profissionalização, entre outros.

Sobre o tema, Andrea Rodrigues Amin escreveu com maestria:

Regulamentando e buscando dar efetividade à norma constitucional, foi promulgado o Estatuto da Criança e do Adolescente, microssistema aberto de regras e princípios, fundado em três pilares básicos: 1) criança e adolescente são sujeitos de direito; 2) afirmação de sua condição peculiar de pessoa em desenvolvimento, e, portanto, sujeito a uma legislação especial; 3) prioridade absoluta na garantia de seus direitos fundamentais. (Curso de Direito da Criança e do Adolescente, Aspectos teóricos e práticos, 2014, p. 53).

O Estatuto da Criança e do Adolescente, em consonância com o art. 227, da Constituição Federal, também previu, de forma expressa, a doutrina da proteção integral da criança e do adolescente. Nesse sentido, encontra-se a redação do art. $3^{\circ}$, senão vejamos:

A criança e o adolescente gozam de todos os direitos fundamentais inerentes à pessoa humana, sem prejuízo da proteção integral de que trata esta Lei, assegurando-se-lhes, por lei ou por outros meios, todas as oportunidades e facilidades, a fim de lhes facultar o desenvolvimento físico, mental, moral, espiritual e social, em condições de liberdade e de dignidade.

Por meio deste dispositivo, podemos perceber que o Estatuto bus- 
ca prever e disciplinar uma gama de instrumentos jurídicos de tutela da criança e do adolescente, que não se esgota, necessariamente, em seus dispositivos. A utilização da expressão, sem prejuízo da proteção integral, permite inferir que é possível a criação de outros diplomas legislativos ou atos normativos, que assegurem pleno desenvolvimento e dignidade às crianças e adolescentes.

Prova disso é que o direito ao respeito, do qual se origina o dever de cuidado do Poder Público e da sociedade em relação às crianças e adolescentes, e é um dos fundamentos da lei aqui tratada, foi previsto no art. 15 do ECA, e não no art. $3^{\circ}$, podendo-se afirmar que mesmo que não houvesse tal previsão seria possível extraí-la através de uma interpretação sistemática de toda a legislação infanto-juvenil.

Entretanto, era necessário dar concretude à proteção integral, razão pela qual, o Estatuto previu a política de atendimento dos direitos da criança e do adolescente por meio de um conjunto articulado de ações governamentais e não-governamentais, das três esferas federativas, por meio de políticas sociais básicas e especiais (art. 86, ECA).

Dessa forma, foi colocado, expressamente, como linha de ação da política de atendimento, serviços especiais de prevenção e atendimento médico e psicossocial às vítimas de negligência, maus-tratos, exploração, abuso, crueldade e opressão (art. 87, III).

É dentro deste contexto que se insere a Lei $\mathrm{n}^{\circ} 13.431 / 17$, que apresenta, pela primeira vez, mecanismos processuais de proteção e prevenção de maiores danos às crianças e adolescentes vítimas ou testemunhas de violência.

No entanto, antes de adentrarmos nos mecanismos específicos trazidos pela lei, necessária se faz uma breve passagem pelos princípios que regem o direito infantojuvenil. 


\section{PRINCÍPIOS DE PROTEÇÃO DOS DIREITOS DA CRIANÇA E DO ADOLESCENTE}

\subsection{Princípio da prioridade absoluta}

Está previsto pelo art. 227, da Constituição Federal, e pelos artigos $4^{\circ}$ e 100, parágrafo único, II, ambos do ECA, que estabelecem a preferência que deve se dar aos interesses da criança e do adolescente, qualquer que seja o cenário (judicial, administrativo, social etc).

A expressão absoluta prioridade impõe assim um dever que recai sobre a família e sobre o poder público de priorizar o atendimento aos direitos infantojuvenis.

A prioridade absoluta está intimamente ligada à proteção integral. Na verdade, pode-se afirmar que o seu objetivo é realizar a proteção integral, assegurando primazia que facilitará a concretização dos direitos fundamentais assegurados pelos diplomas legislativos.

O parágrafo único do art. $4^{\circ}$ do ECA, traz o seguinte conteúdo mínimo à ideia de prioridade absoluta:

Parágrafo único. A garantia de prioridade compreende:

a) primazia de receber proteção e socorro em quaisquer circunstâncias;

b) precedência de atendimento nos serviços públicos ou de relevância pública;

c) preferência na formulação e na execução das políticas sociais públicas;

d) destinação privilegiada de recursos públicos nas áreas relacionadas com a proteção à infância e à juventude.

Fala-se em conteúdo mínimo, pois não estamos diante um rol taxativo, mas de norma de conteúdo aberto, sendo sempre possível ampliar o seu alcance como forma de atingir a proteção integral.

Dessa forma, a família, a sociedade e o Estado devem observar a prioridade absoluta dos interesses do menor, qualquer que seja a área em que estejam inseridos. Aqui está compreendido o dever do 
Poder Público de garantir a eficácia dos direitos previstos no art. 227, da Constituição Federal, e no art. $4^{\circ}$, do Estatuto.

Ao Poder Legislativo, na qualidade Poder Público, também cabe o dever de observância do presente princípio, sendo a edição de leis destinadas à proteção da infância e juventude a manifestação desse dever constitucional.

\subsection{Princípio do melhor interesse}

Esse princípio configura orientação para o legislador e para o aplicador do direito, traduzindo-se na ideia de que, na análise do caso concreto, deve-se buscar solução que proporcione o maior benefício possível para a criança e o adolescente, ou seja, aquela que dê maior concretude aos seus direitos fundamentais.

Nesse sentido, guarda ligação, quase indissociável, com a doutrina da proteção integral, pois ambos buscam proporcionar a dignidade da pessoa em desenvolvimento.

Para Gustavo Ferraz de Campos Mônaco, trata-se "do princípio da dignidade humana aplicada à criança e ao adolescente".

No entanto, na prática, nem sempre se observa a correspondência ao objetivo legal, não sendo raras as vezes em que soluções técnicas, puramente legalistas, esquecem que o destinatário final da doutrina protetiva é a criança e o adolescente.

Assim, durante anos, crianças e adolescentes, vítimas ou testemunhas de violência, foram submetidas a depoimentos constrangedores, por vezes vexatórios, sem que houvesse qualquer preparo ou cuidado para minorar seus efeitos negativos, por conta da preocupação exclusiva com a necessidade de se produzir prova processual.

Cabe ressaltar que não se está propondo a derrogação de normas em nome do princípio do melhor interesse, mas apenas frisar que é dever de todos os aplicadores do direito buscar a materialização deste princípio. 
Sendo certo que a referida técnica viola o melhor interesse da criança, e, consequentemente, a sua proteção integral, foram necessários 27 anos após a edição do Estatuto da Criança e do Adolescente, para que se propusesse um novo modelo que compatibilizasse a produção de provas e demais garantias processuais (ampla defesa e contraditório) com a dignidade das pessoas em condição peculiar de desenvolvimento.

\section{DA LEI 13.431/2017}

\subsection{Antecedentes legais}

Muito antes de se pensar o assunto no Brasil, já havia todo um arcabouço internacional de proteção aos direitos da criança e adolescentes vítimas de violência. Assim, a Convenção sobre os Direitos da Criança de 1990, em seu art. 12, § 2 já garantia o direito da criança ser ouvida e que sua opinião fosse levada em consideração em "todo processo judicial ou administrativo que afete a mesma, quer diretamente quer por intermédio de um representante ou órgão apropriado em conformidade com as regras processuais da legislação nacional".

No entanto, faltava um parâmetro para que essa oitiva pudesse ser realizada, sem gerar danos ao depoente. Dessa forma, adotou-se, em 25 de maio de 2000, o Protocolo Facultativo para a Convenção dos Direitos da Criança, promulgado pelo governo brasileiro (BRASIL, 2004), que reconheceu a necessidade de proteção das crianças vítimas e testemunhas em todos os estágios do processo judicial criminal, obrigando o Estado informar sobre seus direitos e o andamento dos processos, considerar suas opiniões, dando-lhe apoio e protegendo sua privacidade e segurança e evitando demora desnecessária nos processos.

Assim, embora configurem inovação processual, essas formas de 
oitiva da criança e do adolescente já possuíam amparo legal no art. $28, \S 1^{\circ}$, e no art. 100, parágrafo único, ambos do ECA.

No Brasil, o programa "depoimento sem dano" surgiu no Tribunal de Justiça do Rio Grande do Sul, por volta do ano de 2003, por iniciativa do então juiz, atualmente Desembargador, José Antônio Daltoé Cezar, tendo sido adotado por diversos outros juízos ao redor do país.

Em 2010, o Conselho Nacional de Justiça (CNJ) reconheceu a necessidade de um depoimento adaptado à condição da criança, ao editar a Recomendação n. 33/2010 que orienta os tribunais a:

I - implantarem um sistema de vídeogravação em ambiente separado da sala de

audiências;

II - realizarem a escuta com profissionais capacitados no uso da entrevista

cognitiva;

III - esclarecerem a criança ou adolescente sobre o motivo e efeito de seu depoimento;

IV - prestarem apoio e encaminhamentos médicos e assistenciais da vítima e familiares;

V - garantirem o princípio da atualidade, colhendo o depoimento em tempo mais próximo da data do conhecimento do fato.

A jurisprudência também já chancelava essas formas de relato, sempre em observância à proteção integral do menor, entendendo que a aplicação do instituto, mesmo antes da existência de previsão legal, não configurava caso de cerceamento de defesa ou nulidade processual. Vejamos o caso emblemático julgado pelo STJ:

PROCESSUAL PENAL. RECURSO ORDINÁRIO EM HABEAS CORPUS. ESTUPRO DE VULNERÁVEL. OITIVA DA VÍTIMA MEDIANTE “DEPOIMENTO SEM DANO”. CONCORDÂNCIA DA DEFESA. NULIDADE. INEXISTÊNCIA. 1. Esta Corte tem entendido justificada, nos crimes sexuais contra criança e adolescente, a inquirição da vítima na modalidade do "depoimento sem dano", em respeito à sua condição especial de pessoa em desenvolvimento, procedimento admitido, inclusive, antes da deflagração da persecução penal, mediante prova antecipada (HC 226.179/RS, Rel. Ministro 
JORGE MUSSI, QUINTA TURMA, julgado em 08/10/2013, DJe 16/10/2013). 2. A oitiva da vítima do crime de estupro de vulnerável (CP, art. 217-A), em audiência de instrução, sem a presença do réu e de seu defensor não inquina de nulidade o ato, por cerceamento ao direito de defesa, se o advogado do acusado aquiesceu àquela forma de inquirição, dela não se insurgindo, nem naquela oportunidade, nem ao oferecer alegações finais. 3. Além da inércia da defesa, que acarreta preclusão de eventual vício processual, não restou demonstrado prejuízo concreto ao réu, incidindo, na espécie, o disposto no art. 563 do Código de Processo Penal, que acolheu o princípio pas de nullité sans grief. Precedentes. 4. A palavra da vítima nos crimes contra a liberdade sexual, que geralmente são praticados na clandestinidade, assume relevantíssimo valor probatório, mormente se corroborada por outros elementos (AgRg no AREsp 608.342/PI, Rel. Ministro WALTER DE ALMEIDA GUILHERME (DESEMBARGADOR CONVOCADO DO TJ/SP), QUINTA TURMA, julgado em 03/02/2015, DJe 09/02/2015). 5. No caso, além do depoimento da vítima, o magistrado sentenciante, no decreto condenatório, considerou o teor dos testemunhos colhidos em juízo e o relatório de avaliação da menor realizado pelo Conselho Municipal para formar seu convencimento. 6. Recurso ordinário desprovido. STJ - RECURSO ORDINARIO EM HABEAS CORPUS RHC 45589 MT 2014/0041101-2 Data de publicação: 03/03/2015 [grifei]

Entretanto, por mais que a ideia de "depoimento sem dano" pudesse ser extraída das normas, resoluções e julgados elencados acima, havia necessidade de se sistematizar e trazer caráter pedagógico a tais preceitos em norma legal, o que só foi possível com o advento da Lei 13.431/17.

Assim, a novel legislação veio normatizar e organizar o sistema de garantia de direitos da criança e do adolescente vítima ou testemunha de violência, criando mecanismos para prevenir e coibir a continuação desta violência. 


\subsection{Destinatários}

Conforme o artigo $1^{\circ}$, da Lei 13.431/17, os destinatários primeiros das medidas nela previstas são as crianças e os adolescentes, observado o critério biológico previsto pela Constituição Federal e pelo ECA.

No entanto, o artigo $3^{\circ}$, parágrafo único, da mesma lei, amplia os instrumentos inovadores de proteção que poderão ser aplicados de forma facultativa aos jovens entre 18 e 21 anos de idade, em consonância ao artigo $2^{\circ}$, parágrafo único, do ECA, e ao Estatuto da Juventude.

Em que pese à maioridade civil e penal seja atingida aos 18 anos de idade, o legislador, observando que nem sempre a maturidade e o discernimento são critérios meramente cronológicos, previu a possibilidade de pessoas entre 18 e 21 anos de idade, serem beneficiadas com os mecanismos de proteção, em conformidade sempre com o princípio da dignidade da pessoa humana.

\subsection{Espécies de violência}

O legislador, buscando uma ampla tutela dos direitos e interesses dos menores vítimas ou testemunhas de crimes praticados mediante violência, resolveu, no artigo $4^{\circ}$, especificar as modalidades de violência, mas não de forma taxativa, a fim de que a proteção aqui buscada não fique limitada a expressões legais.

No inciso I, foi prevista a violência física, definida como aquela que atinja a integridade ou a saúde corporal do menor, ou que lhe cause sofrimento. É a violência que, de alguma forma, ofenda o corpo físico da criança ou do adolescente.

Já no inciso II, foram previstas formas de violência psicológica, sendo consideradas aquelas que afetem o desenvolvimento psíquico e/ou emocional do menor, como a alienação parental e o bullying, temas atuais e que são clássicos exemplos de agressão à integridade emocional da criança e do adolescente. 
O inciso III trouxe a violência sexual, que pode ser definida como qualquer forma de constrangimento, por meio presencial ou físico, a fim de que o menor pratique ou presencie conjunção carnal ou qualquer outro ato libidinoso.

Por fim, o inciso IV, de forma inovadora, previu a violência institucional, que é a praticada por instituições públicas ou conveniadas, como delegacias de polícia, hospitais, centros de apoio, Judiciário e Ministério Público. Aqui, a violência é praticada justamente por quem tem a atribuição de defesa dos interesses dos menores, mas que, em razão da falta de técnica, acaba gerando a revitimização, que ocorre quando a vítima ou a testemunha são arguidas de maneira que as façam reviver os traumas experimentados no momento do crime, trazendo novamente os sentimentos de angústia e de sofrimento.

\subsection{Finalidade}

A Vitimologia é ramo da criminologia, que tem como objeto de estudo as consequências negativas do delito para vítima.

Segundo os estudiosos da Vitimologia, há três dimensões da vitimização, a primária, a secundária e a terciária. A primeira decorre direta e imediatamente da prática do crime, ou seja, é a pessoa diretamente afetada pela infração criminal. Já a última é aquela que decorre do meio social, que acaba estigmatizando a vítima em razão da prática de certo tipo de delito.

A vitimização secundária, que é a que interessa a este estudo, é a que envolve a vítima primária e o Estado, que exerce o poder punitivo e, assim, a persecução criminal. Além de ter sido atingida pelo crime, a vítima primária ainda terá que se recorrer ao Estado para que seja investigado, processado e julgado o autor do delito, significando que ela terá que se dirigir até a delegacia de polícia, se submeter a exame de corpo de delito, se assim o delito exigir, e ser ouvida novamente, em fase processual, perante um juiz, promotor de justiça e advogado. 
O legislador, sensível à hipervulnerabilidade das crianças e dos adolescentes vítimas e testemunhas de crimes praticados mediante violência, em razão da já mencionada especial condição dessas pessoas em desenvolvimento, trouxe outros mecanismos de proteção desses menores que precisem ser ouvidos perante autoridades que buscam responsabilizar os autores de delitos.

Conforme visto, a lei em estudo está em plena sintonia com a Constituição Federal, o Estatuto da Criança e do Adolescente e a Convenção sobre Direitos da Criança e seus protocolos adicionais, transformando-se em mais um instrumento de proteção integral dos menores que foram vítimas ou presenciaram delitos violentos.

É importante ressaltar que, muitas vezes, o depoimento da vítima é a única fonte de prova, seja por ausência de testemunhas - nos casos em que a violência física ou sexual é intrafamiliar - ou ausência de vestígios - como em alguns crimes sexuais - ou ainda nos casos em que o exame pericial é inconclusivo, em razão do lapso temporal entre a agressão e sua realização.

Assim, o depoimento da vítima torna-se instrumento essencial para a punição do agressor, mas que tem consequências diretas para a própria vítima.

Em recente artigo escrito ${ }^{6}$ por Maria Isabel de Matos Rocha, juíza do Tribunal de Justiça do Estado do Mato Grosso do Sul, ela faz referência a uma passagem (MORGAN; ZEDNER, 2003, p. 115), que afirma que a responsabilização penal do agressor:

(...) primeiro, valida a experiência, deixando claro que o comportamento do ofensor é inaceitável; segundo, uma persecução exitosa pode ajudar a criança a superar a culpa de que normalmente sofre como resultado do ato pelo qual não é responsável e nos quais foi apenas envolvida por causa de sua vulnerabilidade. Finalmente, pode ajudar a quebrar o ciclo de abuso. Um dos mais importantes fatores para a restauração da saúde mental da criança abusada é

6 Disponível em http://www.enfam.jus.br/wp-content/uploads/2017/04/ARTIGO-Depoimento-Especial-MARIA-ISABEL-ROCHA.R5K.pdf. 
de compelir o abusador a assumir responsabilidade pelo que foi feito. Isto apenas pode ser feito se for publicamente reforçada a verdade da palavra da criança, enfatizando que a criança em sentido algum deve ser vista como culpada e veemente se colocar o peso da culpa no ofensor.

A finalidade da lei consiste justamente em preservar o depoimento ou as declarações prestadas em sede administrativa ou em juízo como meio importante de prova, sem que signifique uma extensão dos danos já causados pela ação delituosa, prevendo-se diversos instrumentos de proteção, tais como o depoimento especial e a escuta especializada, como forma de evitar a revitimização (vitimização secundária) de crianças e adolescentes.

\subsection{Dos Direitos e garantias específicos}

Diversos foram os mecanismos de proteção trazidos pelo legislador a fim de proteger a integridade psicoemocional do menor em desenvolvimento, que seja vítima ou testemunha de um delito praticado mediante violência.

Todos esses instrumentos, como já mencionado, buscam evitar a revitimização da criança ou do adolescente, em forma de violência institucional, buscando, na medida do possível, minimizar os já deletérios efeitos do delito praticado contra ou na presença do incapaz.

Os direitos e garantias especiais foram previstos, de maneira não exaustiva, no art. $5^{\circ}$ da já citada lei. Muitas garantias já estavam presentes no próprio Estatuto da Criança e do Adolescente, como o recebimento de prioridade absoluta e ter considerada a condição peculiar de pessoa em desenvolvimento (inciso, I), ser protegido contra qualquer tipo de discriminação (IV), prioridade na tramitação do processo (inciso, VIII). No entanto, na prática, nem sempre essas garantias eram observadas.

Destaca-se que todos os direitos e garantias elencados no citado dispositivo, além de tentarem evitar a revimitização, como já ex- 
planado, buscam tratar a criança e o adolescente como sujeitos de direito, e que, embora em condição peculiar de desenvolvimento, têm o direito de receber informações adequadas sobre direitos, inclusive sociais, serviços disponíveis, representação jurídica, medidas de proteção, reparação de danos e qualquer procedimento a que seja submetido (inciso V).

Cabe ainda ressaltar, que como sujeito de direitos, a autonomia de vontade da criança e do adolescente deve ser respeitada, prevendo-se, expressamente, o direito de ficar em silêncio, caso assim deseje.

Por fim, mas não menos importante, encontra-se a possibilidade de conferir medida protetiva em favor da criança e do adolescente, vítima ou testemunha de violência, contra o seu autor (art. $6^{\circ}$ ), aplicando-se subsidiariamente a Lei Maria da Penha, quando necessário. Embora já fosse possível o deferimento dessas medidas, fundamentando-se no art. $130^{7}$ do ECA e no próprio poder geral de cautela da autoridade judiciária, a previsão expressa na lei traz mais segurança jurídica aos aplicadores do direito e amplia o leque de proteção à criança e ao adolescente.

Como vimos, os institutos processuais precisavam se adequar à proteção integral do menor e, por isso, além dos direitos e garantias já mencionadas, foram inseridos no nosso ordenamento os instrumentos da escuta especializada e do depoimento especial.

\subsubsection{Escuta especializada e depoimento especial}

Os institutos aqui analisados são a espinha dorsal lei em comento, tendo em vista que é frequente a chamada violência institucional, pois, até a edição dessa lei, em regra, o menor, ao ser atendido administrativa ou judicialmente, sofria nova violação de seus direitos

7 Art. 130. Verificada a hipótese de maus-tratos, opressão ou abuso sexual impostos pelos pais ou responsável, a autoridade judiciária poderá determinar, como medida cautelar, o afastamento do agressor da moradia comum.

Parágrafo único. Da medida cautelar constará, ainda, a fixação provisória dos alimentos de que necessitem a criança ou o adolescente dependentes do agressor. 
por quem, na verdade, deveria zelar pela defesa dos seus interesses.

A escuta especializada é procedimento extrajudicial, previsto no art. $7^{\circ}$, da Lei $13.431 / 17$, e tem como finalidade realizar entrevista com a criança ou adolescente vítima ou testemunha de violência. Ocorrerá perante órgão da rede de proteção da criança e do adolescente, sendo que o relato do menor se limitará estritamente ao necessário para a sua proteção, não se admitindo que dados secundários ao delito sejam descortinados por questão de curiosidade do entrevistador, que apenas trarão mais constrangimento e sofrimento.

Já o depoimento especial, antes denominado de "depoimento sem dano", é a forma de colheita de declarações de crianças e de adolescentes, que ocorrerá perante a autoridade policial ou judicial. Ele busca, assim como a escuta especializada, a proteção psicológica das vítimas e testemunhas infantojuvenis. No entanto, o depoimento produzido poderá ser utilizado como prova no processo judicial.

É importante destacar que, embora a lei permita que o depoimento seja realizado perante a autoridade policial ou judicial (art. $8^{\circ}$ ), a norma também prevê, de maneira expressa, que o depoimento será realizado, uma única vez, em sede de produção antecipada de prova judicial, garantida a ampla defesa do investigado (art. 11).

Assim, como forma de preservar a criança e o adolescente, atendendo aos princípios legais da norma em apreço, já especificados acima, entendemos que a melhor maneira de se interpretar esse instituto é que ele seja sempre realizado perante a autoridade judicial, como produção antecipada de provas.

Dessa forma, ao tomar conhecimento de crime em que haja vítima ou testemunha criança ou adolescente, o Delegado de Polícia deverá representar ao Ministério Público (titular da ação penal) para que este órgão requeira a realização do depoimento especial, em sede produção antecipada de prova, perante a autoridade judiciária, garantindo o direito de contraditório do investigado. Essa possibilidade está inclusive prevista na redação do art. 21, VI da lei. 
No nosso entendimento, esta é a única maneira de se preservar a criança e o adolescente e, ao mesmo tempo, garantir o devido processo legal, utilizando o depoimento especial como meio de prova.

A lei ainda traz os requisitos para a realização do ato, prevendo que a audiência deverá ser realizada, de forma simultânea, em duas salas, sendo que, em um recinto reservado, menos constrangedor, a vítima ou a testemunha dará o seu depoimento a um psicólogo ou assistente social. Na sala de audiência propriamente dita, ficarão o juiz, o promotor, o advogado/defensor e o réu, que terão acesso à fala do depoente por meio de transmissão em tempo real do relato.

Os sujeitos processuais que desejarem formular perguntas à vítima, ou à testemunha, farão os questionamentos por intermédio do psicólogo ou assistente social.

O depoimento especial deverá ocorrer em apenas um ato processual. No entanto, é possível nova oitiva do menor, desde que demonstrada a sua imprescindibilidade e que haja a concordância da vítima ou da testemunha ou do seu representante legal.

Como se vê, tanto a escuta especializada quanto o depoimento especial buscam evitar a vitimização secundária, que, como já descrito, ocorre no momento da persecução criminal. Esses dispositivos, conjugados, permitirão amenizar essa situação, já que esses depoimentos serão colhidos em data cada vez mais próxima da data dos fatos, uma única vez, permitindo a retomada da vida da criança e do adolescente sem ter que reviver a todo o momento os episódios traumáticos.

\section{CONCLUSÃO}

A prática de crimes violentos, principalmente sexuais, pode deixar marcas indeléveis nas vítimas. Esses danos se tornam potencialmente mais perigosos naquelas vítimas que estão em condição peculiar de desenvolvimento, como é o caso de crianças e adolescentes. 
Dessa forma, falar sobre o assunto com pessoas com as quais não se tem uma relação de confiança, e que não tenham preparo técnico, significa, na maioria das vezes, reviver todo o transtorno já passado.

Assim, devem-se buscar mecanismos que aliam proteção às vítimas e testemunhas e, ao mesmo tempo, possibilitem a punição do agressor.

Alguns estudos apontam que a sanção penal pode ter um importante papel simbólico para as vítimas, pois, de alguma forma, restabelece o curso que foi quebrado pelo agressor (ROCHA, 2017). Nesse sentido, receber o reconhecimento de sua condição de vítima, pelo sistema judicial, faz com que a vítima deixe de se sentir culpada pela agressão sofrida, o que é bastante comum em crimes violentos, principalmente sexuais.

É aí que entra o papel dos institutos trazidos pela Lei $n^{\circ} 13.431 / 17$, pois permite a produção de prova testemunhal que, em grande parte dos casos, é a única possível, evitando, contudo, a vitimização secundária da criança e do adolescente.

Os principais mecanismos trazidos pela lei foram a escuta especializada e depoimento especial. Como vimos, esses mecanismos já podiam ser extraídos dos princípios que regem o direito da infância e juventude e do próprio Estatuto da Criança e do Adolescente. No entanto, era necessária a sistematização desses institutos, trazendo mais segurança jurídica, não só às vítimas e testemunhas, mas aos operadores do direito.

A sistematização desses mecanismos pela Lei $n^{\circ} 13.431 / 17$ foi um importante avanço no ordenamento jurídico brasileiro, sendo necessário agora viabilizar condições para que esses institutos sejam aplicados na prática. 


\section{TESTIMONIES WITHOUT DAMAGES AND THE SYSTEMATIZA- TION OF THE INSTITUTES OF SPECIALIZED LISTENING AND THE SPECIAL TESTIMONY OF CHILDREN AND ADOLESCENTS (LAW N $\left.{ }^{\circ} 13.431 / 2017\right)$}

\section{ABSTRACT}

The practice of violent crimes, mainly sexual, reaches large layer of the Brazilian population and, in particular, children and adolescents, as a rule, people most vulnerable to this type of violence. The way in which the testimonies of these children and adolescents have been taken, in unknown environments (police station or courtroom), without the technical preparation of the law operators, brings greater damage to those, causing the so-called secondary revictimization or Institutional violence, in which the victim or witness revives the whole rape situation already experienced. It has long been thinking of ways to provide these testimonies, which are often the only source of proof, without causing such damaging effects. The Law $n^{\circ} 13.431 / 2017$ systematized for the first time the institutes of specialized listening and the special testimony, being therefore important advancement for the Brazilian legal order.

Keywords: Child and adolescent. Full protection. Secondary victimization. Specialized listening. Special statement.

\section{REFERÊNCIAS}

AMIN, Andrea Rodrigues. Curso de Direito da Criança e do Adolescente, Aspectos teóricos e práticos. $7^{a}$ Ed. São Paulo, Saraiva: 2014. BRASIL. CONSTIUIÇÃO DA RÉPUBLICA FEDERATIVA DO BRASIL 1988. Disponível em: <http://www.planalto.gov.br/ccivil_03/constituicao/ constituicaocompilado.htm>. Acesso em: 23 nov. 2017.

BRASIL. Estatuto da Criança e do Adolescente. Disponível em: http:// www.planalto.gov.br/ccvil_03/leis/L8069.htm. Acesso em: 20 nov.2017. 
BRASIL. Lei Federal no 13431/201 7. Disponível em: http://www.planalto. gov/ccvil_03/ato201502018/2017/lei/L13431.htm. Acesso em: 25nov.2017. JUS BRASIL. Jurisprudência. Disponível em: http://stj.jusbrasil.com.br/jurisprudência/25044002/recurso-especial-resp-1419421-go-2013-0355585-8-stj/ inteiro-teror-25044003. Acesso em: 10 nov.2015.

JUS BRASIL. Jurisprudência. Disponível em: < https://www.jusbrasil.com.br/ jurisprudencia/busca?q=depoimento+sem+dano >Acesso em: 25 nov. 2017. MINISTÉRIO DOS DIREITOS HUMANOS. Disponível em: < http:// www.mdh.gov.br/disque100/balancos-e-denuncias/balanco-disque-100-2016-apresentacao-completa/ > Acesso em 26 nov. 2017.

MÔNACO, Gustavo Ferraz de Campos. "A proteção da criança no cenário internacional". $1^{\text {a }}$ Ed. Belo Horizonte, Del Rey: 2005, p. 179.

ROCHA, Maria Isabel de Matos ."Depoimento Especial" de crianças e adolescentes vítimas de violência sexual: a experiência do Estado de Mato Grosso do Sul. Disponível em: < http://www.enfam.jus.br/wp-content/ uploads/2017/04/ARTIGO-Depoimento-Especial-MARIA-ISABEL-ROCHA. R5K.pdf > Acesso em: 20 nov.2017. 